\title{
Spontaneous Abdominal Wall Hematoma: A Rare Case Report with Review of Literature
}

\author{
Amit Mittal ${ }^{1 *}$, Sreeramulu $\mathrm{PN}^{2}$, Srinivasan $\mathrm{D}^{3}$ and Savagave $\mathrm{SG}^{4}$ \\ ${ }^{1}$ Department of General Surgery, Sri DevarajUrs Medical College, Kolar \\ ${ }^{2}$ Head and Professor, Department of General Surgery, Sri DevarajUrs Medical College, Kolar \\ ${ }^{3}$ Assistant Professor, Department of General Surgery, Sri DevarajUrs Medical College, Kolar \\ ${ }^{4}$ Department of Radio Diagnosis, Sri DevarajUrs Medical College, Kolar
}

Received: January 04, 2017; Published: February 05, 2018

*Corresponding author: Sreeramulu PN, Department of General Surgery, Head and Professor, Kolar, India,

\begin{abstract}
Introduction: Abdominal wall hematoma, caused by rupture of superficial abdominal vessel (most commonly epigastric vessels) or muscle tear, is most frequently encountered in association with anticoagulation therapy, trauma, operation, and hematologic disorder. It rarely occurs spontaneously.

Case report: We report a case of abdominal wall hematoma in a 55-year-old female without any predisposing factors and not on any anticoagulants. It was managed symptomatically.

Conclusion: Spontaneous Abdominal wall hematoma though a rare identity but should be kept in mind as differential diagnosis as it can have a varied course and has to be treated promptly.

Keywords: Epigastric vessels; Abdominal wall hematoma
\end{abstract}

\section{Mini Review}

Spontaneous rectus sheath hematoma is an uncommon condition which has preponderance for elderly females, particularly on anticoagulant [1] therapy or chronic abdominal straining. It may mimic any acute abdominal disorder. Hence awareness of this rare clinical entity is very important. Computerized Tomography is diagnostic [2] with strong clinical suspicion USG can be enough [3]. The treatment is largely conservative [4]. Here we have described a case of spontaneous rectus sheath hematoma.

\section{Case Report}

Spontaneous abdominal wall hematoma is a rare condition. In this report, we present a case of a 55 Year-old female who came to R.L. Jalapa hospital, casualty with right lower abdominal pain which was sudden in onset and gradually progressive, was stabbing type of pain after a bout of coughing. Was none radiating. The patient had history of cough with expectoration since 5 days which mild in nature and subsided with antitussive and expectorants. She had bluish discoloration in periumbilical and right lumbar and right iliac fossa since one day (Figure 1). There was no past history of fever, vomiting, trauma, any chronic ailment. She did not have any bleeding diathesis and was not on any anti coagulants.
On examination, her vitals were normal. There was tenderness and guarding in periumblical and right iliac fossa. Clinically, differential diagnosis of Acute appendicitis, acute pancreatitis, and rectus sheath hematoma was made. Periumbilical discoloration was thought to be Cullen's sign. On laboratory investigations, her haemoglobin was $10.7 \mathrm{~g} /$ $\mathrm{dL}$, urine examination was normal, total leucocyte count was $11.87 \mathrm{~T} /$ cumm, Blood urea $19 \mathrm{mg} / \mathrm{dL}$, Blood sugar $98 \mathrm{mg} / \mathrm{dL}$, serum sodium $132 \mathrm{~m} \mathrm{Eq/L}$, serum potassium $4.6 \mathrm{mEq} / \mathrm{L}$, serum amylase $75 \mathrm{U} / \mathrm{L}$ and INR was 1.04. Ultrasound (USG) showed. Features concerning for Rectus muscle hematoma versus evolving abscess.

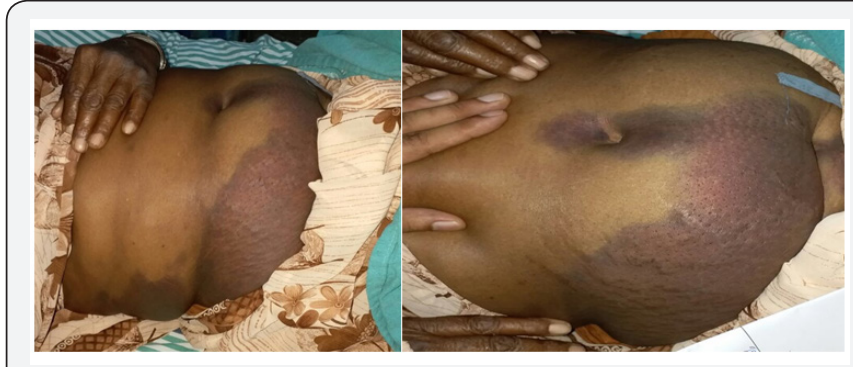

Figure 1: Clinical photograph of the patient. 


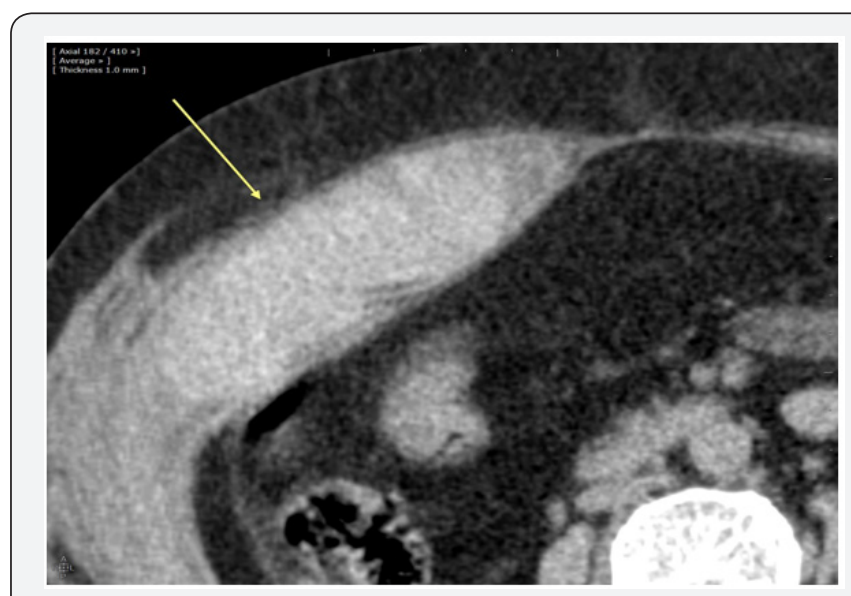

Figure 2: CT abdomen showing hematoma in rectus muscle axial view.

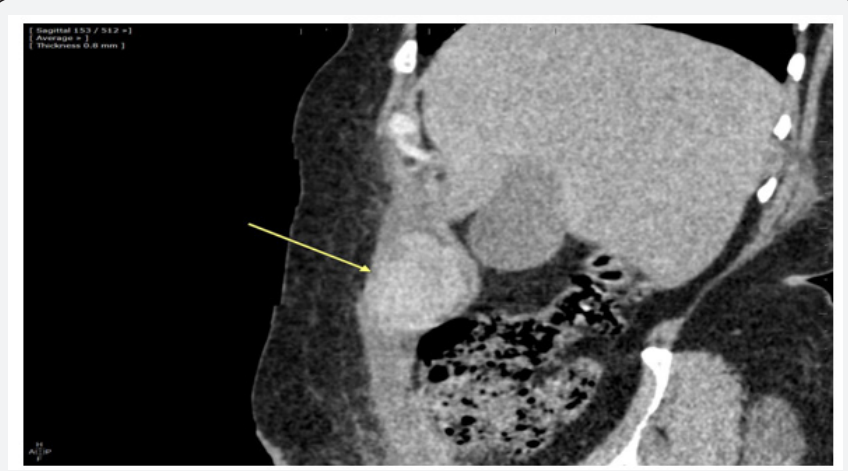

Figure 3: CT abdomen showing hematoma in rectus muscle Saggital view.

Plain CT abdomen (Figure 2 \& 3) revealed diffuse intra muscular hematoma in Right internal oblique and rectus sheath muscle based on these investigations, diagnosis of spontaneous rupture of inferior epigastric artery was made. She was treated conservatively and had improved symptomatically. At 2 months follow up her skin discoloration had completely resolved.

\section{Discussion}

The rupture of epigastric artery leading to rectus sheath hematoma is well described in the literature [5-7]. Anatomically, the inferior epigastric artery ascends between posterior rectus sheath and rectus abdominis muscle. The loose attachment of the branches of inferior epigastric artery to the muscle puts it under stretch during strong muscular contractions. Moreover, cases with vascular degeneration are further prone to vessel rupture even with mild cough [8]. Superior epigastric artery traverses the abdominal wall between posterior sheath and rectus muscle until it anastomoses with the inferior epigastric artery at the level of umbilicus. The rupture of superior epigastric artery is much rare.

There are many predisposing factors known to cause rectus sheath hematoma viz. anticoagulants, coughing [8], sneezing, lifting heavy weight, straining at stools or micturition, abdominal wall trauma, previous or recent abdominal surgery, subcutaneous injection, cardiovascular disease and pregnancy. Out of these, most common factor is anticoagulant therapy. Although, there are several reports of spontaneous rectus sheath hematoma, but most of the times, the precipitating factors are not recognized. The typical presentation is acute abdominal pain, nausea, vomiting and fever. On examination, hematoma is felt as a lump in the abdominal wall above the arcuate line in superior epigastric artery rupture and below the arcuate line in inferior epigastric artery rupture.

The lump may not be always palpable because it is situated deep to the rectus abdominis muscle, especially in obese patients. On leg raising in supine position, the lump becomes fixed and more tender due to its 7 location in the abdominal wall. (Fother gill sign). Most of the cases can be managed conservatively and operative intervention should be avoided [9]. But in cases where haemorrhage continues Angio-embolization should be considered [10-12].

\section{References}

1. Klinger PJ, Oberwalder MP, Riedmann B, Devault KR (2000) Rectus sheath hematoma clinically masquerading as sigmoid diverticulitis. Am J Gastroenterol 95(2): 555-556.

2. Berná JD, Garcia Medina V, Guirao J, Garcia Medina J (1996) Rectus sheath hematoma: diagnostic classification by CT. Abdom Imaging 21(1): 62-64.

3. Shokoohi H, Boniface K, Taheri MR, Pourmand A (2013) Spontaneous rectus sheath hematoma diagnosed by point-of-care ultrasonography. Canadian Journal of Emergency Medicine 15(2): 120-123.

4. Zainea GG, Jordan F (1988) Rectus sheath hematomas: their pathogenesis, diagnosis, and management. Am Surg 54(10): 630-633.

5. Siu WT, Tang CN, Law BK, Chau CH, Li MK (2003) Spontaneous rectus sheath hematoma. Canadian journal of surgery 46(5): 390.

6. Payne RL (1938) Spontaneous rupture of the superior and inferior epigastric arteries within the rectus abdominis sheath. Ann Surg 108(4): 757-768.

7. Pascual MM (2014) Spontaneous rectus sheath hematoma in a third level hospital. A retrospective study. European Congress of Radiology $1-20$.

8. Caglayan K, Celik A (2010) Spontaneous lateral abdominal wall hematoma as a complication of coughing: Case report and literature review. Journal of Experimental and Clinical Medicine 27: 38-38.

9. Sarkar M, Mitra S (2016) Want to operate an abdominal lump? Think twice; it might be spontaneous rectus sheath hematoma: a case report. International Journal of Research in Medical Sciences 4(9): 42084211.

10. Lee DE, Ahn JY, Moon S (2017) A Case of Rectus Sheath Hematoma with Spontaneous Inferior Epigastric Artery Injury Treated Successfully by Angio-embolization 28(4).

11. Murray SD, Burger RE (1954) Rupture of the inferior epigastric vessels. Annals of surgery 139(1): 90-94.

12. Sarma DR, Farago V, Watson M, Adamek J (2015) Spontaneous Rectus Sheath Haematoma Less is More. Journal of Surgery and Surgical Research 1(3): 033-034. 


\section{Open Access Journal of Surgery}

This work is licensed under Creative Commons Attribution 4.0 Licens

DOI: 10.19080/OAJS.2018.08.555726
Your next submission with Juniper Publishers will reach you the below assets

- Quality Editorial service

- Swift Peer Review

- Reprints availability

- E-prints Service

- Manuscript Podcast for convenient understanding

- Global attainment for your research

- Manuscript accessibility in different formats

( Pdf, E-pub, Full Text, Audio)

- Unceasing customer service

Track the below URL for one-step submission

https://juniperpublishers.com/online-submission.php 